\title{
Clinical Profile of Acute Respiratory Distress Syndrome: Two Years Experience at a Tertiary Care Center
}

\author{
Vijaykumar V Ingle ${ }^{1}$, Swapnil Bade ${ }^{2}$

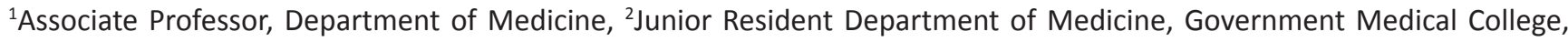 \\ Jalgaon, Maharashtra, India
}

Corresponding author: Dr Vijaykumar V Ingle c/o Shridhar R Kulkarni Block No 40/41 Abhimanshri Nagar, Murarji Peth, Solapur 413001 Maharashtra, India

DOI: $10.21276 /$ ijcmsr.2018.3.2.40

How to cite this article: Vijaykumar V Ingle, Swapnil Bade. Clinical profile of acute respiratory distress syndrome: two years experience at a tertiary care center. International Journal of Contemporary Medicine Surgery and Radiology. 2018;3(2):B171-B173.

\section{A B S T R A C T}

Introduction: Acute Respiratory Distress Syndrome is a critical illness associated with significant morbidity and mortality. This study was designed to study clinical characteristics and outcome of ARDS patients.

Material and methods: An observational retrospective analysis of 60 patients of ARDS admitted at Medical Intensive Care Unit of a tertiary care teaching hospital for a period of 2 years. This study included 60 consecutive ARDS patients who fulfilled the AECC definition of ARDS.Patients who were not on mechanical ventilator were excluded from study.

Results: There were more males than females. Common etiological causes of ARDS were pneumonia, tropical infections including malaria and sepsis. Mortality was observed in $60 \%$ cases.

Conclusion: ARDS is one of the important causes of mortality in ICU patients.

Key words: Acute Respiratory Distress Syndrome.Ventilator induced lung injury, Mortality

\section{INTRODUCTION}

Acute respiratory distress syndrome (ARDS), and its milder form acute lung injury (ALI), are a spectrum of lung diseases characterized by a severe inflammatory process causing diffuse alveolar damage and resulting in a variable degree of ventilation perfusion mismatch, severe hypoxemia, and poor lung compliance. ${ }^{1}$

The lung injury may be direct, as occurs in toxic inhalation, or indirect, as occurs in sepsis. Acute lung injury (ALI) is a less severe disorder but has the potential to evolve into $\mathrm{ARDS}^{2}$ The mortality rate in patients with ARF exceeds $40 \%$, and the mortality after ARDS is considered to be in excess of $50 \%$. Recent data, however, suggests a significant decrease in ARDS mortality, although the explanation for this observation remains unclear. The problem with the lack of a uniform definition of ARDS has been addressed by the American-European Consensus Conference on ARDS which has provided a definition for ALI and ARDS for future research. ${ }^{3}$

The American-European Consensus Conference (AECC) proposed a definition, which is now widely accepted as a simple diagnostic tool for patient characterization and research trial conduct. There are three diagnostic criteria for ARDS: the presence of acute severe hypoxemia (defined as a ratio of arterial oxygen tension over fractional inspired oxygen $\left(\mathrm{PaO}_{2} / \mathrm{FiO}_{2}\right)<200 \mathrm{~mm} \mathrm{Hg}(26.7 \mathrm{kpa})$ ), bilateral infiltrates on chest radiography (CXR), and the absence of raised pulmonary artery wedge pressure. If the $\mathrm{PaO}_{2} / \mathrm{FiO}_{2}$ is $>200 \mathrm{~mm} \mathrm{Hg}$ and $<300 \mathrm{~mm} \mathrm{Hg}$ the criteria for ALI are met. $^{4}$

Reported mortality rates vary widely. A pooled mortality estimate from a recent systematic review suggests that the mortality for ARDS is between 36-44\%, with little change over the two decades up to 2006. In contrast to this, the ARDS Network clinical trials conducted over the last two decades show a clear decline in mortality among their study populations between 1997 and 2009.5,6

So this study was designed to study clinical characteristics and outcome of ARDS patients.

\section{MATERIAL AND METHODS}

This was retrospective observational study of 60 patients of acute respiratory distress syndrome admitted at Medical Intensive Care unit of teaching hospital in northern Maharashtra. The study period was between Jan 2015 to Dec 2017. Study was approved by ethical committee of the institution and informed consent was taken before the start of study.

The inclusion criteria were based on the American/European consensus statement for definition of ALI and ARDS,

1 Acute Onset

$2 \mathrm{PaO}_{2} / \mathrm{FiO}_{2}$ ratio less than 200 regardless of PEEP level

3 Bilateral infiltrates seen on chest radiograph

4 Pulmonary Artery Wedge pressure less than $18 \mathrm{~mm} \mathrm{Hg}$ or no clinical evidence of left atrial hypertension. ${ }^{4}$

Patients who did not require mechanical ventilation were excluded from study. 
A case record form was developed and validated by local experts for collection of data. Ethical approval was obtained from local institution level committee.

Patients demographic details like name, age, sex, date of admission, vital signs, laboratory investigations, etiologies, comorbidities, site of referral, maximum APACHE II score, $\mathrm{PaO}_{2} / \mathrm{FiO}_{2}$ ratio, duration of ICU stay, mode of mechanical ventilation, duration of mechanical ventilation, maximum PEEP used, maximum tidal volume recorded, duration of steroid therapy, complications and mortality data were recorded in case record form.

\section{STATISTICAL ANALYSIS}

Statistical analysis was done with the help of Microsoft office 2007. Descriptive statistics like mean and percentages were used for the analysis.

\section{RESULTS}

We studied 60 patients of ARDS who fulfilled the abovementioned inclusion and exclusion criteria. Various demographic features and other clinical characteristics are presented in the following tables. As shown in table 1 , there were more males than females (48 out of total 60 ). From table 2 , it can be inferred that most of the patients were referred from Emergency department.

\begin{tabular}{|l|c|}
\hline Demographic Variable & Value \\
\hline Age (mean) & 48 \\
\hline Male gender(\%) & $42(70)$ \\
\hline Most frequent comorbidities & 18 \\
\hline Hypertension & 10 \\
\hline Diabetes Mellitus & 04 \\
\hline \multicolumn{2}{|l|}{ Ischemic heart dis } \\
\hline \multicolumn{2}{|c|}{ Table-1: Demographic characteristics of 60 patients of ARDS } \\
\hline
\end{tabular}

\begin{tabular}{|l|c|}
\hline Referral Origin & Number \\
\hline Emergency dept & 27 \\
\hline Intermediate care unit & 08 \\
\hline Operative room & 04 \\
\hline Surgical ward & 03 \\
\hline Medical ward & 12 \\
\hline Ortho ward & 02 \\
\hline Other hosp & 04 \\
\hline \multicolumn{2}{|c|}{ Table-2: Characteristics of 60 patients in relation to referral } \\
origin \\
\hline
\end{tabular}

\begin{tabular}{|l|c|}
\hline Variable & Value \\
\hline Mean APACHE II Score & 21.6 \\
\hline Number of organ system failure(mean) & 05 \\
\hline Length of ICU stay(days) & 10 \\
\hline Etiology Pneumonia including Tropical infections & 28 \\
\hline Aspiration of gastric Contents & 02 \\
\hline Sepsis & 26 \\
\hline Acute pancreatitis & 03 \\
\hline Severe non thoracic Injury & 01 \\
\hline Mean $\mathrm{PaO}_{2} /$ FiO & 92 \\
\hline \multicolumn{2}{|c|}{ Table-3: Etiologic profile of patients of ARDS } \\
\hline
\end{tabular}

\begin{tabular}{|l|c|}
\hline Variable & Value \\
\hline Duration of MV (days) & 10 \\
\hline Predominant Ventilation mode Pressure control & 50 \\
\hline Volume Control & 10 \\
\hline Maximum PEEP(Cm H2O) & 13.1 \\
\hline Maximum tidal vol (ml/IBW) & 8.1 \\
\hline Steroid therapy & 16 \\
\hline Pneumothorax after initiation of MV & 08 \\
\hline \multicolumn{2}{|c|}{ Table-4: Therapy and Mechanical Ventilation Strategies } \\
\hline
\end{tabular}

\begin{tabular}{|l|c|c|}
\hline Total & 60 & $100 \%$ \\
\hline Survived & 24 & $40 \%$ \\
\hline Not survived & 36 & $60 \%$ \\
\hline \multicolumn{2}{|c|}{ Table-5: Outcome of patients } \\
\hline
\end{tabular}

Common etiological factors of ARDS were Pneumonia and Sepsis.

Mean $\mathrm{PaO}_{2} / \mathrm{FiO}_{2}$ on admission was 92. All patients were on mechanical ventilation. Most of the patients were managed on pressure control ventilation and mean tidal volume delivered was $8.1 \mathrm{ml} /$ ideal body weight. (Table 3 and 4 ) Mean duration for which patients were put on ventilatory support was 10 days. Total mortality observed was $60 \%$.

\section{DISCUSSION}

This was a retrospective study of 60 patients of Acute Respiratory Distress Syndrome conducted at a tertiary care teaching hospital. The primary objective of our study was to analyze the clinical characteristics of ARDS patients. As shown above the etiological profile, ventilatory strategies and outcome was also studied in great detail.

The primary targets for ARDS treatment are to ensure adequate gas exchange while minimizing the risk of VILI. Current recommendations for mechanical ventilation via endotracheal intubation emphasize lower tidal volumes based on a patient's predicted body weight. PEEP remains a mainstay in the ventilatory strategy for acute lung injury, although the method for determining the optimal level of PEEP has not been established.

The main determinant of VILI is the ratio between the size of tidal volume and that of the resting lung volume in which it is distributed: together, they determine the nonphysiologic stress (tension generated within the lung tissue) and strain (deformation of the lung). Then, to maintain a low stress and strain we need a low tidal volume or a high resting volume. A seminal study on ventilator strategy in ARDS (the ARMA trial), demonstrated how using a tidal volume of $6 \mathrm{~mL} / \mathrm{kg}$ (predicted body weight), as compared to the then conventional setting of $12 \mathrm{~mL} / \mathrm{kg}$, a $22 \%$ reduction in mortality could be achieved..$^{1,7}$

In our study,as shown in results, gender distribution had male predominance. This finding was similar to study conducted by Hemptinne et al in which 59\% of ARDS patients were males. ${ }^{8}$

Pneumonia, sepsis were the primary etiological causes of ARDS in our study population. A study conducted by $\mathrm{Lu}$ et al also reported Sepsis (30\%) as major etiologic cause of ARDS. ${ }^{9}$ 
Mean $\mathrm{PaO}_{2} / \mathrm{FiO}_{2}$ ratio on admission in our patients was 92 and Ziberberg and Epstein found similar mortality rate in patients with $\mathrm{PaO}_{2} / \mathrm{FiO}_{2}$ less than $200 .{ }^{10}$

Mean stay in MICU was 10.4 days and average in hospital mortality in our study was observed in 60\% which was more than that observed during recent studies. In past two decades there are studies from world claiming that mortality has decreased to up to $30 \%$. Study done by Widdermann et al had observed mortality of 30\%, which may have been as a result of improvement in the specific management of patients of ARDS such lung protective ventilation as well as in the general management of ICU patients. ${ }^{11}$

However in another study in India by Agrawal R et al, the mortality rates were again higher. ${ }^{12}$

\section{CONCLUSION}

ARDS has high mortality rate (60\% in our study). The most common risk factors for mortality in ARDS were: pneumonia and sepsis and low $\mathrm{PaO}_{2} / \mathrm{FiO}_{2}$ ratio.

\section{REFERENCES}

1. Ware LB, Matthay MA.The acute respiratory distress syndrome. N Engl J Med 2000;342(1):1334-49

2. Anthony S. Fauci, Dennis L. Kasper, Dan L. Longo, Eugene Braunwald, Stephen L. Hauser,J.LarryJameson, Joseph Loscalzo, (editors). Harrison's Principles Of Internal Medicine Seventeenth Edition. The McGrawHill Companies, Inc. Chapter 262. Acute Respiratory Distress Syndrome

3. Luhr OR,Antonsen $\mathrm{K}$,Karlsson $\mathrm{M}$,et al. Incidence and mortality after acute respiratory failure and acute respiratory distress syndrome in Sweden, Denmark, and Iceland. The ARF Study Group. Am J Respir Crit Care Med 1999;159(2):1849-61.

4. Bernard G.R., Artigas A., Brigham K.L., Carlet J., Falke K., Hudson L., Lamy M., Legall J.R., Morris A., Spragg R. The american-european consensus conference on ards. Definitions, mechanisms, relevant outcomes, and clinical trial coordination. Am. J. Respir. Crit. Care Med. 1994;149(3):818-824.

5. Phua J,Badia JR,Adhikari NK,et al. Has mortality from acute respiratory distress syndrome decreased over time? A systematic review. Am J Respir Crit Care Med 2009;179(6):220-7

6. Spragg RG, Bernard GR,Checkley W,et al. Beyond mortality: future clinical research in acute lung injury. Am J Respir Crit Care Med 2010;181(5):1121-7

7. Wiedemann H.P., Arroliga A.C., Fisher C.J., Komara J.J., Perez P., Parsons P.E., Wolkin R., Welsh C., Fulkerson W.J., MacIntyre N., et al. Ventilation with lower tidal volumes as compared with traditional tidal volumes for acute lung injury and the acute respiratory distress syndrome. The acute respiratory distress syndrome network. N. Engl. J. Med. 2000;342(4):13011308

8. Hemptinne Q, Remme Link $m$, Brimioulle S, Salmon I, Vincent JL. ARDS: A Clinicopathological Confrontation. Chest 2009;135(4):944-949.

9. Lu j, Song Z, Zhan X, Huang S, Zhu D, Yang C, Bai X et al. A 12 month survey of incidence and outcome of acute respiratory distress syndrome in Shanghai intensive care units. Intensive Care Med.2004;30(12):2197-203.

10. Ziberberg, Epstein S K. Acute lung injury in medical ICU: comorbid conditions, age, etiology and hospital outcome. Am J Respir Crit Care Med 1998;157(1):115964.

11. Wiedemann HP, Wheeler AP, Bernard GR et al. The National Heart Lung and Blood institute Acute Respiratory Syndrome (ARDS) Clinical Trials Network Comparison of Two Fluid Management Strategies in Acute Lung Injury. N Engl J Med 2006;354(3):256473.

12. Agrawal R, Aggarwal AN, Gupta D, Behera D, Jindal SK. Etiology and outcomes of pulmonary and extrapulmonary acute lung injury/ARDS in a respiratory ICU in north India. Chest 2006;130(4):724-29.

\section{Source of Support: Nil; Conflict of Interest: None}

Submitted: 20-05-2018; Accepted: 24-06-2018; Published online: 05-07-2018 